This item was submitted to Loughborough's Research Repository by the author.

Items in Figshare are protected by copyright, with all rights reserved, unless otherwise indicated.

\title{
A kinetic model for whey protein denaturation at different moisture contents and temperatures
}

PLEASE CITE THE PUBLISHED VERSION

https://doi.org/10.1016/j.idairyj.2017.07.002

\section{PUBLISHER}

(C) Elsevier

VERSION

AM (Accepted Manuscript)

\section{PUBLISHER STATEMENT}

This work is made available according to the conditions of the Creative Commons Attribution-NonCommercialNoDerivatives 4.0 International (CC BY-NC-ND 4.0) licence. Full details of this licence are available at: https://creativecommons.org/licenses/by-nc-nd/4.0/

\section{LICENCE}

CC BY-NC-ND 4.0

\section{REPOSITORY RECORD}

Atuonwu, James C., Joydeep Ray, and A.G.F. Stapley. 2017. "A Kinetic Model for Whey Protein Denaturation at Different Moisture Contents and Temperatures". figshare. https://hdl.handle.net/2134/26426. 


\title{
A Kinetic Model for Whey Protein Denaturation at Different Moisture Contents and Temperatures
}

\author{
James C. Atuonwu ${ }^{\dagger}$, Joydeep Ray ${ }^{\ddagger}$, Andrew G.F. Stapley*
}

Department of Chemical Engineering, Loughborough University,

Loughborough, Leicestershire, LE11 3TU, UK.

† Present address: Centre for Sustainable Energy use in Food Chains, Brunel University, Uxbridge, Middlesex, UB8 3PH, U.K.

‡Present address: Nestlé Research Center, Vers-chez-les-Blanc, 1000 Lausanne 26, Switzerland.

${ }^{*}$ Corresponding author:

Tel.: +441509222525

E-mail address: A.G.F.Stapley@Lboro.ac.uk 


\section{Abstract:}

The denaturation of whey protein samples that had previously undergone heattreatment for different times at different temperatures and moisture contents was analysed by Differential Scanning Calorimetry (DSC), using the DSC enthalpy as a measure of residual undenatured protein. Data were fitted to first order irreversible or reversible kinetic expressions, and the resulting rate constants were found to increase with both temperature and moisture content. The whole data set was then fitted as a function of time, temperature and moisture content, with rate constants varying according to either Arrhenius or Williams-Landel-Ferry (WLF) kinetics and with selected fit parameters made empirical functions of moisture content. The best fits were obtained using reversible WLF kinetics, which could be further slightly simplified without loss of accuracy. The model provides a platform for single- and multi-objective drying trajectory optimization with respect to protein denaturation in dairy products. 


\section{Introduction}

Proteins are highly desirable components in food products because of their high nutritional value and contributions to sensory attributes such as colour, flavour and texture. Whey proteins, in particular, play a huge role due to the widespread consumption of dairy produce. Constituting about $20 \%$ of the proteins in milk, they have the highest biological value among all known proteins (Anandharamakrishnan et al., 2007; Wijayanti et al., 2014). They are used as additives in formulated products such as bakery products, processed meats, beverages, pasta, ice cream, confectionery, infant foods, spreads, dips and as encapsulating agents in pharmaceuticals.

For convenience and to extend their shelf life, liquid dairy products are often subjected to dehydration processes such as evaporation and spray drying. Spray drying, in particular, is the generally accepted method for producing dry powder. The dehydration process involves thermal treatment, during which whey proteins can lose their normal secondary, tertiary or quaternary structures. Denaturation, as this process is called, transforms the protein from its native folded, biologically active state to an unfolded, biologically inactive state. Physically, this can manifest in aggregation, coagulation, reduced solubility for powders and loss of some functional properties such as gelling and emulsification (Haque et al., 2013a, b). In addition, the denaturation of whey proteins is accompanied by the release of small sulfur-containing compounds such as methanethiol and hydrogen sulfide which produce cooked flavours in heated milk (AlAttabi, et al., 2009). The aggregation that results from denaturation can potentially lead to processing downtime due to heat exchanger fouling and nozzle blocking in spray dryers. Consequently, whey protein denaturation is a major issue in dairy processing. 
The study of denaturation during spray drying is complicated by the variation of moisture content and temperature with both position in the droplet/particle and time. Understanding the mechanism of whey protein denaturation with the ability to predict its extent over a wide range of process and product conditions is important for deriving dehydration strategies to minimise this phenomenon. For this, reliable kinetic models are required. Studies on the thermal denaturation of whey proteins abound in the literature (e.g. Wolz and Kulozik, 2015; Dissanayake et al., 2013; Lamb et al., 2013; Oldfield et al., 2005), especially in fully hydrated systems (Wolz and Kulozik, 2015). However, most of these studies have not examined how denaturation behaviour varies with moisture content. An exception is the work of Haque et al. (2013a, b), who investigated the denaturation of whey protein isolate solutions in suspended droplets whilst drying. They assumed a model equation used by Meerdink and van't Riet (1995) for enzyme inactivation to describe the variation of kinetics with temperature and moisture content. This was inserted into a drying model which predicted the moisture content and temperature history of the droplets from which the kinetic parameters for the denaturation were inferred via inverse model fits. However, this experimental study focused mainly on high moisture content levels ( $40 \%$ and above), over a limited temperature range $\left(65\right.$ and $\left.80^{\circ} \mathrm{C}\right)$, and with results sampled at $60 \mathrm{~s}$ intervals, which exceeds the times for most commercial spray drying operations. Moreover, since the experiments were in a convective drying environment, continuous temperature and moisture content variations occurred, as a result of which the denaturation kinetics at constant temperature and moisture levels were not resolved (two experiments were performed at constant temperature and moisture content but these appear to have been at high moisture contents only). Therefore, although it is well known that protein damage occurs at temperatures above $60^{\circ} \mathrm{C}$ in fully wet systems, little understanding exists on the ability of proteins to withstand heat when in a partially dried state. 
Quantifying the simultaneous impact of moisture levels and temperatures on protein denaturation kinetics will better enable the development of optimum dehydration profiles with respect to protein denaturation. Such an approach has been undertaken with assessing lysine losses in dairy powders, whereby powders were equilibrated at different water activities (using salt solutions) and then subjected to thermal treatment in hermetically sealed cans for different time-temperature combinations (Schmitz et al., 2011; Schmitz-Schug et al., 2014).

This work presents a similar experimental approach, using thermal treatment in combination with partial hydration, followed by Differential Scanning Calorimetry (DSC) analysis to generate experimental data that quantify the combined effects of time, temperature and moisture content on whey protein denaturation. From this, a set of four mathematical models have been derived in a three-step process to explicitly describe the denaturation kinetics. The models are based on a combination of either first-order reversible or irreversible kinetics, with rate constant temperature dependencies expressed using either Williams-Landel-Ferry (WLF)-type or Arrhenius equations. Semi-mechanistic monotonic functions of moisture content are proposed for some of the parameters, so a global fit of the whole data set can then be made as functions of time, temperature and moisture content. The four mathematical models are then compared and possibilities for optimising drying processes considered.

\section{Materials and methods}

\subsection{Experimental}

10-20 mg of as-received low-heat Whey Protein Isolate (WPI) powder (Impact Whey isolate, MyProtein, Northwich, UK) were loaded into high-pressure stainless steel DSC 
pans (TA Instruments, New Castle, DE), and weighed. The samples used in the experiment were obtained from products manufactured using a combination of membrane filtration and low-temperature drying to avoid protein denaturation prior to the experiment. The composition (w/w) of the WPI powder stated by the manufacturer is $90 \%$ protein, $2.5 \%$ lactose, $0.3 \%$ fat, $0.5 \%$ salt and $6.7 \%$ other (including moisture). Samples were equilibrated with different saturated salt solutions to various intermediate moisture levels over a few days. The salts used were Magnesium Chloride (Acros Organics, Fair Lawn, NJ), Sodium Chloride (Fisher Scientific, Fair Lawn, NJ) and Potassium Chloride (Hopkin and Williams Limited, Harrogate, UK) to yield equilibrium moisture levels as detailed in Table 1. The relationship between the water activity generated by the saturated salt solutions and the equilibrium moisture level is based on the sorption isotherms for WPI powder presented by Foster et al. (2005). The equilibration vessels were $1000 \mathrm{ml}$ Kilner jars to which $100 \mathrm{ml}$ of RO (reverse osmosis) water was added, and an excess of the desired salt such that crystals were always present. A total of 10 loaded DSC pans were placed on a Petri dish, which was then placed on a raised platform within the jar, which was located above the level of the salt solution. The jars were placed in a water bath at $25^{\circ} \mathrm{C}$. The pans were weighed at daily intervals until no significant further change in mass was observed (a second Petri dish was used to cover the pans to minimise any changes in moisture content whilst samples were outside of the Kilner jar). Other dry basis moisture content $\left(\mathrm{kg} \mathrm{kg}^{-1}\right)$ levels investigated were 0 (absence of moisture, from vacuum drying the as-received powder at ambient temperature for 24 hours), 0.05 (the initial moisture content of the as-received powder) and 2.5 (full hydration). Samples were then sealed and heated in either a stirred water bath (for temperatures $<100^{\circ} \mathrm{C}$ ) or a silicone oil bath $\left(>100^{\circ} \mathrm{C}\right)$, for different times. The pans were then plunged into a beaker of cold water, removed, dried on the outside, and then opened and water 
added to the samples using a micropipette (to a ratio $1: 2.5 \mathrm{w} / \mathrm{v}$ ) to ensure full hydration as required for DSC analysis (Anandharamakrishnan et al., 2007). All mass measurements were performed with Sartorius microbalances (Sartorius AG, UK) of accuracy $0.1 \mathrm{mg}$.

The pans were then resealed and analysed by DSC (Q10, TA Instruments), together with an identical but empty reference pan. In the DSC analysis, the sample and reference were first equilibrated at $20^{\circ} \mathrm{C}$, and then heated at a linear rate of $5^{\circ} \mathrm{C} / \mathrm{min}$ to $100^{\circ} \mathrm{C}$. The experiments were performed in triplicate. Protein denaturation was observed in the peaks produced in the heat flow-temperature diagram. The area under the peak is produced by the denaturation in the DSC of any undenatured proteins left in the sample after the previous heat treatment in the water/oil bath. It is thus a measure of the amount of undenatured proteins left after heat treatment. Enthalpies were obtained assuming a linear baseline, and were compared to those of a hydrated sample of as-received powder, which was used as a reference. The latter yielded the highest enthalpy which was taken to represent zero denaturation (or $100 \%$ native protein concentration). The fractional decrease in enthalpy from this value was then taken to be the fraction of denaturation that occurred in the sample during the previous heat treatment.

\subsection{Mathematical modelling}

The existing literature on whey protein denaturation kinetic models (e.g. Dissanayake et al., 2013; Haque et al., 2013a, b; Oldfield, et al., 1998; Wolz \& Kulozik, 2015, among others) can be categorised into $1^{\text {st }}, 2^{\text {nd }}$ and higher-order models with Arrhenius rate constant temperature dependencies. The majority of these models are concerned with whey protein components either individually or in milk, whey and model systems without specific reference to moisture content effects. The overall denaturation process 
has been described as a two-step process consisting of a conditionally-reversible unfolding step, and a subsequent irreversible aggregation step (Chen et al., 1998; Parris et al., 1991; Tolkach \& Kulozik, 2007).

In this work, two rate constant temperature dependencies, the Williams-Landel-Ferry (WLF)-type and the Arrhenius equations were tested in conjunction with both reversible and irreversible first order kinetic models. Both $2^{\text {nd }}$ order and "nth" order kinetic models were also tested, but these generally gave poorer fits to data and were therefore discarded.

The moisture content dependence was then built in by making some of the WLF or Arrhenius parameters functions of moisture content. The overall modelling strategy was performed in three stages.

In the first stage, concentration vs time data were fitted to first-order reversible and irreversible kinetics, which have the following rate laws, respectively:

$$
\begin{aligned}
& \frac{d c}{d t}=-k_{f} c+k_{r}\left(c_{0}-c\right) \\
& \frac{d c}{d t}=-k_{i} c
\end{aligned}
$$

where $c$ represents the concentration (or fraction) of undenatured proteins, $c_{0}$ the initial value of $c$, such that $\left(c_{0}-c\right)$ represents the concentration of denatured proteins. $k_{f}$ and $k_{r}$ are the rate constants of the forward and reverse reactions respectively for the reversible kinetic model, while $k_{i}$ is the rate constant for the irreversible kinetic model.

Upon integration (since rate constants do not vary with time) these yield, respectively:

$$
c=\frac{c_{0}}{k_{f}+k_{r}}\left(k_{r}+k_{f}\left(\exp \left(-\left(k_{f}+k_{r}\right) t\right)\right)\right)
$$


$\left.c=c_{0} \exp +k_{i} t\right)$

For the reversible scheme an equilibrium constant can be defined as:

$K_{\text {eq }}=\frac{k_{f}}{k_{r}}$

Value for $k_{i}, k_{f}, k_{r}$ (and hence $K_{e q}$ ) were obtained for each combination of moisture content and temperature by fitting concentration vs time data using a least squares method. This allowed an initial assessment of how these parameters vary with temperature and moisture content.

In stage two the temperature variation was explicitly modelled. At each moisture content, the rate constants $\left(k_{f}\right.$ and $\left.k_{i}\right)$ were assumed to vary with temperature according to either WLF-type (equations 6, 7) or Arrhenius (equations 8, 9) equations:

$k_{f}=k_{f T d} 10 \frac{-C_{1 f}\left(T-T_{d f}\right)}{C_{2 f}+T-T_{d f}}$

$k_{i}=k_{i T d} 10^{\frac{-C_{1 i}\left(T-T_{d i}\right)}{C_{2 i}+T-T_{d i}}}$

$k_{f}=k_{0 f} \exp \left(-\frac{E_{A f}}{R T}\right)$

$k_{i}=k_{0 i} \exp \left(-\frac{E_{A i}}{R T}\right)$

The term "activation energy" is routinely used in conjunction with the Arrhenius equation. It is used here purely as a parameter which models the temperature dependence of the rate constant, rather than quantifying an actual activation energy barrier (as protein unfolding is generally regarded to be driven instead by differences in 
thermodynamic stability between folded and unfolded states). It was found that attempting to model the reverse rate constant $\left(k_{r}\right)$ using similar equations to those above produced sporadic results in a full simulation. Instead, a more reliable method was to model the equilibrium constant, and use this together with the forward rate constant to deduce the reverse rate constant (linked via equation 5). The temperature variation of the equilibrium constant was modelled using the van't Hoff equation for both the Arrhenius and WLF-type dependencies respectively as:

$$
\begin{aligned}
& K_{\text {eq }}=K_{\text {eqref (WLF ) }} \exp \left(-\frac{E_{\text {Aeq }(W L F)}}{R}\left(\frac{1}{T}-\frac{1}{T_{\text {ref }(W L F)}}\right)\right) \\
& K_{\text {eq }}=K_{\text {eqref (Arr ) }} \exp \left(-\frac{E_{\text {Aeq (Arr) }}}{R}\left(\frac{1}{T}-\frac{1}{T_{\text {ref (Arr ) }}}\right)\right)
\end{aligned}
$$

The full parameter list for each of the resulting four models is shown in Table 2. These models (in combination with equation 3 or 4 as appropriate) were fitted to concentration data using the least squares method. Fits were initially made to data pertaining to specific moisture contents, so that individual fits for each parameter in Table 2 were produced for each moisture content. However, trends in the resulting fit parameters were unclear. This was attributed to over-parameterisation (redundancy), which made the fits susceptible to the effects of noise. To combat this, based on observations made in stage one of the fitting process, some parameters $\left(T_{\text {ref }}, T_{d}, k_{T d}\right.$ and $\left.K_{\text {eqref }}\right)$ were made constant across all moisture contents, whilst the remaining parameters were allowed to assume different values for different moisture contents. This concluded stage two of the fitting process.

The resulting fit parameters were then fed to the final third stage, where the moisture varying parameters from stage two were made explicit functions of moisture content 
(as also performed by Schmitz-Schug et al., 2014). The functional forms were empirically derived from the moisture content variation of the fit parameters obtained in stage two, as follows:

For the reversible WLF model,

$$
\begin{aligned}
& C_{1 f}=\frac{C_{1 f \max }}{1+A_{f} \exp \left(-\alpha_{f} X\right)} \\
& E_{\text {Aeq }(W L F)}=E_{\text {Aeq } W L F \text { \$o }}+\left(E_{\text {Aeq } W L F+1}-E_{\text {Aeq } W L F \text { so }}\right)\left(1-\exp \left(-\varepsilon_{W L F} W\right)\right)
\end{aligned}
$$

where $X$ is the dry basis moisture content $\left(\mathrm{kg} \mathrm{kg}^{-1}\right)$ and $W$ is the solids fraction defined as:

$W=\frac{1}{1+X}$

For the reversible Arrhenius model,

$$
\begin{aligned}
& k_{0 f}=\exp \left(\frac{k_{0 f \max }}{1+B_{f} \exp \left(-\beta_{f} X\right)}\right) \\
& E_{\text {Aeq (Arr) }}=E_{\text {Aeq (Arr jo }}+\left(E_{\text {Aeq (Arr }) 1}-E_{\text {Aeq (Arr fo }}\right)\left(1-\exp \left(-\varepsilon_{\text {Arr }} W\right)\right)
\end{aligned}
$$

For the irreversible WLF model,

$$
C_{1 i}=\frac{C_{1 i \max }}{1+A_{i} \exp \left(-\alpha_{i} X\right)}
$$

For the irreversible Arrhenius model,

$$
k_{0 i}=\exp \left(\frac{k_{0 i(A r r)}}{1+B_{i} \exp \left(-\beta_{i} X\right)}\right)
$$


$E_{A i}=\frac{E_{A i \max }}{1+G_{i} \exp \left(-\gamma_{i} X\right)}$

The model performances were judged using the $R^{2}$ and adjusted $R^{2}$ values where $N_{p}$ is the number of parameters in each model, and $N$, the total number of data points:

$$
\begin{aligned}
& R^{2}=1-\frac{\sum\left(c_{\exp }(T, X, t)-c_{f i t}(T, X, t)\right)^{2}}{\sum\left(c_{\exp }(T, X, t)-\bar{c}_{\exp }(T, X, t)\right)^{2}} \\
& R^{2} A d j=1-\left(1-R^{2}\right)\left(\frac{N}{N-N_{p}-1}\right)
\end{aligned}
$$

\section{Results and discussion}

3.1. Experimental results and first stage of the kinetic analysis

Fig. 1 shows example DSC thermograms for samples after 2 minutes of isothermal hold at (a) different temperatures (at $X=0$ ) and (b) different moisture contents (at $T=$ $90^{\circ} \mathrm{C}$ ). It can be seen that increasing either the sample moisture or temperature results in a reduction of the residual denaturation peak, indicating that more denaturation occurred during the previous isothermal hold. The same trends were observed across all samples. For wet samples, it is very well established that increasing the temperature produces a more rapid denaturation, but this can now be seen across the whole moisture content range. It is also seen that the presence of moisture promotes denaturation. This agrees with findings reported by Haque et al. (2013a). The presence of more moisture might also improve heat transfer within the pans, but as this is considered only to affect temperatures within the first minute of heat treatment (or less) it is unlikely to explain the large differences in behaviour observed. 
The first stage of the kinetic analysis was to plot for each moisture content the firstorder reversible and irreversible rate constants (equations 3, 4 and 5) and equilibrium constants against temperature and inverse temperature, as shown in Fig. 2. As expected, for each moisture content, the rate constant increases with temperature. It can also be seen that an increase in moisture content brings about an increase in the rate constant for the same temperature. From the left-hand plots of Fig. 2, it is generally observed that there is a near-linear relationship between the log of the forward and irreversible rate constants and temperature, with the gradients rising as moisture contents increase. Hence, as moisture content drops, progressively higher temperatures are needed to achieve the same effect. The exception to this rule are the rate constants for the $X=2.5$ data which appear to level off at $\sim 80-90^{\circ} \mathrm{C}$. A similar "sharp bend" was also observed by Tolkach \& Kulozik (2007) at a similar temperature in their study of $\beta$-lactoglobulin at high hydration. Tolkach \& Kulozik proposed that the change in slope was due to a change in limiting mechanism. Below $90^{\circ} \mathrm{C}$ the kinetics are limited by the initial unfolding step, and above $90^{\circ} \mathrm{C}$ they are limited by the subsequent aggregation step. The rationale was that DSC endotherms of denaturation of hydrated samples tend to finish at around $87^{\circ} \mathrm{C}$, and as these are sensitive to the unfolding rather than aggregation step, this suggests that this step is complete by $90^{\circ} \mathrm{C}$. Another possible explanation is a thermal lag effect, in that heat transfer into the pans (or, in Tolkach \& Kulozik's case, steel tubes) becomes a rate limiting factor when the experimental time scales become short (at high reaction rates). This is possible as in the experiments reported here, the effect was only seen when rate constants exceeded $3 \mathrm{~min}^{-1}\left(\log _{10} k=0.5\right)$ which only occurred with the fully hydrated samples. At lower temperatures, the rate constant lines appear to converge such that there is a temperature at which the rate constant becomes independent of moisture content (and is also very low). This can be viewed as a base or reference temperature $T_{d}$, and the 
rate of denaturation at any temperature $T$, is essentially dependent on the difference between this temperature and $T_{d}$, with slight nonlinearities. This and the near-linear relationship of the plots in Fig 2, tends to favour a WLF-type form of equation (rather than an Arrhenius type), but with the glass transition temperature $T_{g}$ in the normal WLF equation replaced by $T_{d}$ (see equations 5 and 6 ). However, a fundamental difference between the standard WLF equation and the one used here is that $T_{d}$ (unlike $T_{g}$ ) is independent of moisture content. The link with moisture content (which explains differences in rate constants as $T>T_{d}$ ) can be established through the $C$-parameters. From the left-hand plots of Fig. 2, $T_{d}$ can be projected to be between 60 and $70^{\circ} \mathrm{C}$ for the reversible kinetics and 50 and $70^{\circ} \mathrm{C}$ for the irreversible kinetics (as will be confirmed by fitting results presented in the next section). The presence of these apparent convergence points was the rationale behind the use of the modified WLF equation, and also the reason why the parameters $T_{d f}, T_{d i}, k_{f T d}$ and $k_{f T i}$ were assumed constant in the second stage of the kinetic analysis.

The equilibrium constant $K_{e q}$ (top-right of Fig. 2) also tends to increase with moisture content and temperature. The $K_{\text {eq }}$ lines appear to converge at a point between 50 and $70^{\circ} \mathrm{C}$. Consequently, $T_{\text {ref(WLF) }}, T_{\text {ref(Arr) }}, K_{\text {eqref(WLF) }}$ and $K_{\text {eqref(Arr) }}$ were also assumed constant in the second stage of the kinetic analysis.

The complete set of fitting results from the second stage of the modelling process is shown in Table 3 . Some parameters, notably $C_{1 f}$ and $C_{1 i}$ from the WLF models, and $k_{0 f}, k_{0 i}, E_{A e q(A r r)}$ and $E_{A i}$ from the Arrhenius models showed evidence (in Table 3) of a sigmoidal variation with moisture content $X$, as the values appear to reach a limiting value as $X$ is increased. This would make sense physically as once the proteins have become fully hydrated the effect of additional water should not make any further difference. Sigmoidal functions of $X$ were therefore chosen to represent these 
quantities in the global model. This is different to the functions used by Schmitz-Schug et al. (2014) for lysine loss, as that exhibited an optimum intermediate moisture content where reaction rates were highest.

\subsection{Final parameter fitting results: models and data comparison}

The globally fitted values of the model parameters from the final (third) fitting stage are presented in Table 4. Good agreement is observed between the experimental data and the four models in most cases, with the WLF-type models performing better than the Arrhenius-based models as seen in the table of $R^{2}$ and adjusted- $R^{2}$ values (Table 5). Of these, the reversible-WLF model performs the best, both in terms of $\mathrm{R}^{2}$ and adjusted- $R^{2}$, suggesting that the superior performance is due to its better predictive power, rather than just the higher number of parameters.

Figs. $3-6$ show examples of the denaturation kinetic data (undenatured protein concentration against time) compared with the different model fits at different temperatures and moisture contents. The slower kinetics associated with lower moisture contents can be seen by the higher temperatures used in Fig. $4(X=2.5)$ compared to Fig. $3(X=0.23)$, to achieve similar denaturation. For certain combinations of moisture content and temperature (e.g. $X=2.5$ and $T=65^{\circ} \mathrm{C} ; X=$ 0.23 and $T=80^{\circ} \mathrm{C} ; X=0,0.05,0.08$ and $T=100^{\circ} \mathrm{C}-$ see Figs $\left.3-5\right)$, it can be seen from the data that denaturation is incomplete even at long times, which justifies the use of the reversible equilibrium model to fit the data. In reality, it is unlikely that denatured proteins are able to convert back to undenatured proteins, but the value of the reversible equation is its ability to predict a non-zero concentration after an infinite time, i.e. $c_{e q}=k_{r} c d\left(k_{f}+k_{r}\right)$ (from equation 3), which could be useful in extrapolating results to low-temperature systems. The reversible models are also observed to have excellent performance in fitting the early kinetics (the first 2 minutes) of denaturation; 
approaching an $\mathrm{R}^{2}$ of about 0.99 for this range. This is particularly important for short residence-time dehydration processes such as spray drying.

In terms of the model parameter values and equation behaviours, the following are observed. First, the base denaturation temperature $\left(T_{d}\right)$ used by the reversible WLF model is $65^{\circ} \mathrm{C}$ as against $58^{\circ} \mathrm{C}$ for the irreversible WLF model. This is possibly due to the existence of the reverse kinetic $k_{r}=k_{f} / K_{e q}$ term, which tends to limit denaturation in the reversible model, leading to the requirement of a higher temperature (compared to the irreversible model) to initiate the denaturation process. Also, the moistureindependent reference temperatures in the equations for the equilibrium constants $T_{\text {ref(WLF) }}$ and $T_{\text {ref(Arr) }}$ are 54 and $58^{\circ} \mathrm{C}$ respectively. These results, obtained from the global fitting agree with our earlier postulations from the preliminary kinetic analysis of Fig. 2.

The $C_{2 f}$ value in the reversible WLF model is very high and dwarfs the $\left(T-T_{d}\right)$ term, suggesting that the denominator term in the WLF exponent $\left(C_{2 f}+T-T_{d}\right)$ is unnecessary and can be dispensed with. This reduces the number of fit parameters by one. The resulting equation is thus of the form:

$k_{f}=k_{f T d} 10^{\beta\left(T-T_{d f}\right)}$

where

$\beta=\frac{C_{1 f}}{C_{2 f}}=\frac{\left(C_{1 f \max } / C_{2 f}\right)}{1+A_{f} \exp \left(-\alpha_{f} X\right)}=\frac{\beta_{\max }}{1+A_{f} \exp \left(-\alpha_{f} X\right)}$

The fitted value of $\beta_{\max }$ is $0.181 \mathrm{~K}^{-1}$ (the same as the ratio $C_{1 f \max } / C_{2 f}$ from the reversible WLF model) with the other parameter values as given in Table 4 from the reversible 
WLF model. The functional form of equation 22 also exactly mirrors the linear relationships observed in Fig 2.

In all the models, the model parameters are explicit algebraic functions of moisture content. This ensures easy computation of protein denaturation within usually complex drying models described by partial differential equations. The models thus provide a platform for drying trajectory optimization with respect to protein denaturation in dairy products.

\subsection{Possibilities for drying trajectory optimisation}

Usually, in the optimization of drying processes, many variables are considered simultaneously. These may include energy consumption or quality indicators such as protein stability. Hence, it is important to know if there exists a Pareto space within which the same performance can be achieved, to enhance multi-objective optimization possibilities. Lines of equal native protein concentration derived from the reversible WLF model are shown in Fig. 7 (only three lines 10\%, 50\% and 90\% native protein concentrations are shown). These indicate that for each processing time, there is a family of temperature-moisture content combinations that achieve equal denaturation (raising the moisture content lowers the temperature required). The Pareto space is seen to exist within a strip (from $0 \%$ to $100 \%$ protein concentration), and of course, optimization will usually aim towards the top part of the strip. The width of the space is observed to increase with processing time. For low moisture content values, the operating line of equal denaturation is sensitive to both moisture content and temperature changes. However, as moisture content rises, it becomes independent of moisture content but still strongly sensitive to temperature changes. The operating window of process conditions for which the same denaturation can occur is thus, predicted by the model (the same trend is also seen also for the other models). Hence, 
the models serve as useful inputs for multi-criteria optimization in cases where conflicts exist between protein levels (as a quality indicator) and some other processing objective, as is often the case in practice.

In general, as seen from the surface plots of protein denaturation (Fig. 8), the denaturation kinetics are very fast for very high temperature-moisture content combinations. As time progresses, more lower temperature-moisture content combinations, "push upwards", towards achieving complete (100\%) denaturation, with increased steepness lying on the high-temperature side. Hence, the models can be used in fixing the end-time of the dehydration process based on desired objectives.

\section{Conclusions}

DSC analysis of heat treated whey protein samples clearly shows that the rate of protein denaturation is an increasing function of moisture content as well as temperature. At lower temperatures, the data showed that denaturation is unlikely to go to completion, even after very long times. This was reflected in the model fits which showed the reversible models having a better performance.

Better model fits were found with the WLF-type temperature dependency formulation than the commonly used Arrhenius formulation. The best combination of complexity and accuracy was a simplification of the reversible WLF model in which the denaturation rate varies exponentially with the difference between the processing temperature and a moisture-independent reference temperature. The model provides reaction rate constants as explicit functions of temperature and moisture content and this permits easy computation of protein denaturation within usually complex drying models. They thus provide a platform for drying trajectory optimization with respect to protein denaturation in dairy products. The models also establish operating windows of 
process conditions for which the same denaturation occurs. They are thus useful inputs for multi-criteria optimization in cases where conflicts exist between protein levels (as a quality indicator) and some other processing objective as is often the case in practice. The models can be used to predict denaturation in variable moisture and temperature systems, and incorporated into spray drying and other dehydration models. However a recommendation for future work is to assess whether the presence of other components (such as lactose or salt) have any effect on denaturation kinetics over and above changes to water activity.

\section{Acknowledgement}

The research leading to these results has received funding from the European Research Council under the European Union's Seventh Framework Programme (FP7/2007-2013)/ ERC grant agreement no. 613732 - ENTHALPY - www.enthalpy$\underline{\text { fp7.eu }}$

\section{References}

Al-Attabi, Z., D’Arcy, B. R., \& Deeth, H. C. (2009). Volatile sulphur compounds in UHT milk. Critical Reviews in Food Science and Nutrition, 49, 28-47.

Anandharamakrishnan, C., Rielly, C. D., \& Stapley, A. G. F. (2007). Effects of process variables on the denaturation of whey proteins during spray drying. Drying Technology, 25, 799-807.

Chen, X. D., Chen, Z. D., Nguang, S. K., \& Anema, S. (1998). Exploring the reaction kinetics of whey protein denaturation/aggregation by assuming the denaturation step is reversible. Biochemical Engineering Journal, 2, 63-69.

Dissanayake, M., Ramchandran, L., Donkor, O. N., \& Vasiljevic, T. (2013). Denaturation of whey proteins as a function of heat, $\mathrm{pH}$ and protein concentration. International Dairy Journal, 31, 93-99. 
Foster, K. D., Bronlund, J. E., \& Paterson, A. H. J. (2005). The prediction of moisture sorption isotherms for dairy powders. International Dairy Journal, 15, 411-418.

Haque, M.A., Aldred, P., Chen, J., Barrow, C.J., \& Adhikari, B. (2013a). Comparative study of denaturation of whey protein isolate (WPI) in convective air drying and isothermal heat treatment processes. Food Chemistry, 141, 702-711.

Haque, M. A., Putranto, A., Aldred, P., Chen, J., \& Adhikari, B. (2013b). Drying and denaturation kinetics of whey protein isolate (WPI) during convective air drying process. Drying Technology, 31, 1532-1544.

Lamb, A., Payne, F., Xiong, Y. L., \& Castillo, M. (2013). Optical backscatter method for determining thermal denaturation of $\beta$-lactoglobulin and other whey proteins in milk. Journal of Dairy Science, 96, 1356-1365.

Meerdink, G., \& van't Riet, K. (1995). Prediction of product quality during spray drying. Food and Bioproducts Processing, 73(C4), 165-170.

Oldfield, D. J., Singh, H., \& Taylor, M. W. (2005). Kinetics of heat-induced whey protein denaturation and aggregation in skim milks with adjusted whey protein concentration. Journal of Dairy Research, 72, 369-378.

Oldfield, D. J., Singh, H., Taylor, M. W., \& Pearce, K. N. (1998). Kinetics of denaturation and aggregation of whey proteins in skim milk, heated in an ultrahigh temperature (UHT) pilot plant. International Dairy Journal, 8, 311-318.

Parris, N., Purcell, J. M., \& Ptashkin, S. M. (1991). Thermal denaturation of whey proteins in skim milk. Journal of Agricultural \& Food Chemistry, 39, 2167-2170.

Schmitz, I., Gianfrancesco, A., Kulozik, U., \& Foerst, P. (2011). Kinetics of Lysine Loss in an Infant Formula Model System at Conditions Applicable to Spray Drying. Drying Technology, 29, 1876-1883.

Schmitz-Schug, I., Kulozik, U., \& Foerst, P. (2014). Reaction Kinetics of Lysine Loss in a Model Dairy Formulation as Related to the Physical State. Food and Bioprocess Technology, 7(3), 877-886.

Tolkach, A., \& Kulozik, U. (2007). Reaction kinetic pathway of reversible and irreversible thermal denaturation of $\beta$-lactoglobulin. Lait, 87, 301-315. 
Wijayanti, H. B., Bansal, N., \& Deeth, H. C. (2014). Stability of Whey Proteins during Thermal Processing: A Review. Comprehensive Reviews in Food Science and Food Safety, 13, 1235-1251.

Wolz, M., \& Kulozik, U. (2015). Thermal denaturation kinetics of whey proteins at high protein concentrations. International Dairy Journal, 49, 95-101. 


\section{Nomenclature}

Symbol

Meaning

Unit

$A, B, G$

Model parameters

$c$

$\mathrm{C}_{1}$

Fraction of undenatured protein

$\%$

WLF-type parameter 1

$\mathrm{C}_{2} \quad$ WLF-type parameter 2

E Energy (specific)

$\mathrm{J} \mathrm{mol}^{-1}$

Rate constant

$\min ^{-1}$

$K \quad$ Equilibrium constant

$N \quad$ Total number of data points

$N_{p} \quad$ Total number of model parameters

$R \quad$ Gas constant

$\mathrm{J} \mathrm{mol}^{-1} \mathrm{~K}^{-1}$

$R^{2} \quad$ Coefficient of determination

$t \quad$ Time

$\min$

$T \quad$ Temperature

${ }^{\circ} \mathrm{C}, \mathrm{K}$

W

Solids fraction

$\mathrm{kg} \mathrm{kg}^{-1}$

$X \quad$ Moisture content (dry basis)

$\mathrm{kg} \mathrm{kg}^{-1}$

$\alpha, b, \gamma, \varepsilon$

Model steepness factors

$\mathrm{kg} \mathrm{kg}^{-1}$

\section{Subscripts}

0

$-1$

A

Adj

Arr

d

$\exp$

eq

f

fit

i

$\max$

$r$

ref

WLF
Initial, at temperature $=\infty$

at $X=-1(W=\infty)$

at $X=\infty$

Activation

Adjusted

Arrhenius

Minimum denaturation

Experimental data

Equilibrium

Forward

Fitted value

Irreversible

Maximum

Reverse

Reference

Williams-Landel-Ferry 


\section{Table 1.}

Water activities and corresponding WPI equilibrium moisture of saturated salt solutions

\begin{tabular}{lcc}
\hline Salt & Water activity & $\begin{array}{c}\text { Equilibrium moisture content, } \\
\text { dry basis }\left(\mathrm{kg} \mathrm{kg}^{-1}\right)\end{array}$ \\
\hline Magnesium chloride & 0.33 & 0.08 \\
Sodium chloride & 0.75 & 0.18 \\
Potassium chloride & 0.86 & 0.23 \\
\hline
\end{tabular}

Table 2

Fit parameters used in the second stage of model development.

\begin{tabular}{lccccccc}
\hline Model & \multicolumn{7}{c}{ Parameters } \\
\hline WLF Reversible & $k_{f T d}$ & $C_{1 f}$ & $C_{2 f}$ & $T_{d f}$ & $K_{\text {eqref(WLF) }}$ & $E_{\text {Aeq(WLF) }}$ & $T_{\text {ref(WLF) }}$ \\
Arrhenius Reversible & $k_{\text {of }}$ & $E_{A f}$ & & & $K_{\text {eqref(Arr) }}$ & $E_{\text {Aeq(Arr) }}$ & $T_{\text {ref(Arr) }}$ \\
WLF Irreversible & $k_{f T d}$ & $C_{1 i}$ & $C_{2 i}$ & $T_{d f}$ & & & \\
Arrhenius Irreversible & $k_{0 i}$ & $E_{A i}$ & & & & & \\
\hline
\end{tabular}


Table 3

Fitted parameter values from second stage fits for different moisture contents $(X)$.

\begin{tabular}{|c|c|c|c|c|c|c|c|}
\hline & & $x=0$ & $x=0.05$ & $X=0.08$ & $x=0.18$ & $x=0.23$ & $X=2.5$ \\
\hline \multicolumn{8}{|c|}{ WLF reversible } \\
\hline$C_{1 f}$ & & -79.39 & -94.90 & -111.3 & -196.8 & -218.1 & -1000 \\
\hline$E_{\text {Aeq(WLF) }}$ & $\mathrm{JK}^{-1} \mathrm{~mol}^{-1}$ & 76910 & 76910 & 94890 & 118500 & 197100 & 394200 \\
\hline$K_{\text {eqref(WLF) }}$ & & 0.0129 & 0.0128 & 0.0129 & 0.0129 & 0.0128 & 0.0129 \\
\hline$k_{f T d}$ & $\min ^{-1}$ & \multicolumn{6}{|c|}{0.0316} \\
\hline$C_{2 f}$ & $\mathrm{~K}$ & \multicolumn{6}{|c|}{5533.4} \\
\hline$T_{d f}$ & ${ }^{\circ} \mathrm{C}$ & \multicolumn{6}{|c|}{65.1} \\
\hline$T_{\text {ref(WLF) }}$ & ${ }^{\circ} \mathrm{C}$ & \multicolumn{6}{|c|}{54.1} \\
\hline \multicolumn{8}{|c|}{ Arrhenius reversible } \\
\hline$k_{\text {of }}$ & $\min ^{-1}$ & $2.715 \mathrm{E} 7$ & $5.320 \mathrm{E} 7$ & 7.7995E7 & $3.352 \mathrm{E} 8$ & $5.400 \mathrm{E} 8$ & 4.985E9 \\
\hline$E_{\text {Aeq(Arr) }}$ & $\mathrm{J} \mathrm{K}^{-1} \mathrm{~mol}^{-1}$ & 73530 & 73530 & 79050 & 113700 & 153500 & 361800 \\
\hline$E_{A f}$ & $\mathrm{~J} \mathrm{~K}^{-1} \mathrm{~mol}^{-1}$ & \multicolumn{6}{|c|}{62640} \\
\hline$K_{\text {eqref(Arr) }}$ & ${ }^{\circ} \mathrm{C}$ & \multicolumn{6}{|c|}{0.0197} \\
\hline$T_{\text {ref(Arr) }}$ & ${ }^{\circ} \mathrm{C}$ & \multicolumn{6}{|c|}{58.0} \\
\hline \multicolumn{8}{|c|}{ WLF irreversible } \\
\hline$C_{1 i}$ & & -13.11 & -14.58 & -16.73 & -22.56 & -27.27 & -70.80 \\
\hline$k_{f T d}$ & $\min ^{-1}$ & \multicolumn{6}{|c|}{70960} \\
\hline$C_{2 i}$ & $\mathrm{~K}$ & \multicolumn{6}{|c|}{341.6} \\
\hline$T_{d f}$ & ${ }^{\circ} \mathrm{C}$ & \multicolumn{6}{|c|}{57.8} \\
\hline \multicolumn{8}{|c|}{ Arrhenius irreversible } \\
\hline$k_{0 i}$ & $\min ^{-1}$ & 7.907E9 & $7.898 \mathrm{E} 11$ & $1.505 \mathrm{E} 13$ & $4.584 \mathrm{E} 17$ & 7.616E19 & $1.095 \mathrm{E} 33$ \\
\hline$E_{A i}$ & $\mathrm{~J} \mathrm{~K}^{-1} \mathrm{~mol}^{-1}$ & 83320 & 96080 & 104000 & 130300 & 142900 & 222700 \\
\hline
\end{tabular}


Table 4.

Final fitted parameter values for the WLF and Arrhenius models

\begin{tabular}{|c|c|c|c|c|c|}
\hline \multicolumn{6}{|c|}{ Reversible } \\
\hline \multicolumn{3}{|c|}{ WLF } & \multicolumn{3}{|c|}{ ARR } \\
\hline Parameter & Value & Unit & Parameter & Value & Unit \\
\hline$k_{f T d}$ & 0.0316 & $\min ^{-1}$ & $k_{\text {ofmax }}$ & 22.33 & $\min ^{-1}$ \\
\hline$C_{1 f \max }$ & -1000 & & $B_{f}$ & 0.3208 & \\
\hline$A_{f}$ & 11.85 & & $\beta_{f}$ & 4.647 & $\mathrm{~kg} \mathrm{~kg}^{-1}$ \\
\hline$\alpha_{f}$ & 5.406 & $\mathrm{~kg} \mathrm{~kg}^{-1}$ & $E_{A f}$ & 62640 & $\mathrm{~J} \mathrm{~K}^{-1} \mathrm{~mol}^{-1}$ \\
\hline$C_{2 f}$ & 5533 & $\mathrm{~K}$ & $K_{E Q r e f(A r r)}$ & 0.0197 & \\
\hline$T_{d f}$ & 65 & ${ }^{\circ} \mathrm{C}$ & $E_{A Q \operatorname{ref}(A r r) \infty}$ & $4.901 \mathrm{E}+05$ & $\mathrm{~J} \mathrm{~K}^{-1} \mathrm{~mol}^{-1}$ \\
\hline$K_{E Q r e f(W L F)}$ & 0.0122 & & $E_{A Q \operatorname{ref}(\text { Arr }-1}$ & $-3.384 E+06$ & $\mathrm{~J} \mathrm{~K}^{-1} \mathrm{~mol}^{-1}$ \\
\hline$E_{A Q \operatorname{ref}(W L F) \infty}$ & 530000 & $\mathrm{~J} \mathrm{~K}^{-1} \mathrm{~mol}^{-1}$ & $\varepsilon_{\text {Arr }}$ & 0.1174 & $\mathrm{~kg} / \mathrm{kg}$ \\
\hline$E_{A Q \operatorname{ref}(W L F)-1}$ & $-5.664 E+09$ & $\mathrm{~J} \mathrm{~K}^{-1} \mathrm{~mol}^{-1}$ & $T_{r e f(A r r)}$ & 54.6 & ${ }^{\circ} \mathrm{C}$ \\
\hline$\varepsilon_{W L F}$ & 8.14E-05 & $\mathrm{kg} \mathrm{kg}^{-1}$ & & & \\
\hline$T_{\text {ref( }(W L F)}$ & 54 & ${ }^{\circ} \mathrm{C}$ & & & \\
\hline \multicolumn{6}{|c|}{ Irreversible } \\
\hline \multicolumn{3}{|c|}{ WLF } & \multicolumn{3}{|c|}{ ARR } \\
\hline Parameter & Value & Unit & Parameter & Value & Unit \\
\hline$k_{i T d}$ & $7.18 \mathrm{E}-04$ & $\min ^{-1}$ & $k_{0 i(A r r)}$ & 76.08 & $\min ^{-1}$ \\
\hline$C_{1 \text { imax }}$ & -70.81 & & $B_{i}$ & 2.338 & \\
\hline$A_{i}$ & 4.652 & & $\beta_{i}$ & 5.487 & $\mathrm{~kg} \mathrm{~kg}^{-1}$ \\
\hline$\alpha_{i}$ & 4.523 & $\mathrm{~kg} \mathrm{~kg}^{-1}$ & $E_{\text {Aimax }}$ & 223000 & $\mathrm{~J} \mathrm{~K}^{-1} \mathrm{~mol}^{-1}$ \\
\hline$C_{2 i}$ & 341.6 & $\mathrm{~K}$ & $G_{i}$ & 1.672 & \\
\hline$T_{d i}$ & 58 & ${ }^{\circ} \mathrm{C}$ & $\gamma_{i}$ & 4.772 & $\mathrm{~kg} \mathrm{~kg}^{-1}$ \\
\hline
\end{tabular}

Table 5.

$\mathbf{R}^{2}$ and Adjusted- $\mathbf{R}^{2}$ values for the different models

\begin{tabular}{lccc}
\hline Model Type & Number of parameters & $\mathrm{R}^{2}$ & Adjusted-R $^{2}$ \\
\hline Reversible WLF & 11 & 0.9128 & 0.9067 \\
Irreversible WLF & 6 & 0.9006 & 0.897 \\
Reversible Arrhenius & 9 & 0.8953 & 0.8887 \\
Irreversible Arrhenius & 6 & 0.8555 & 0.8493 \\
\hline
\end{tabular}




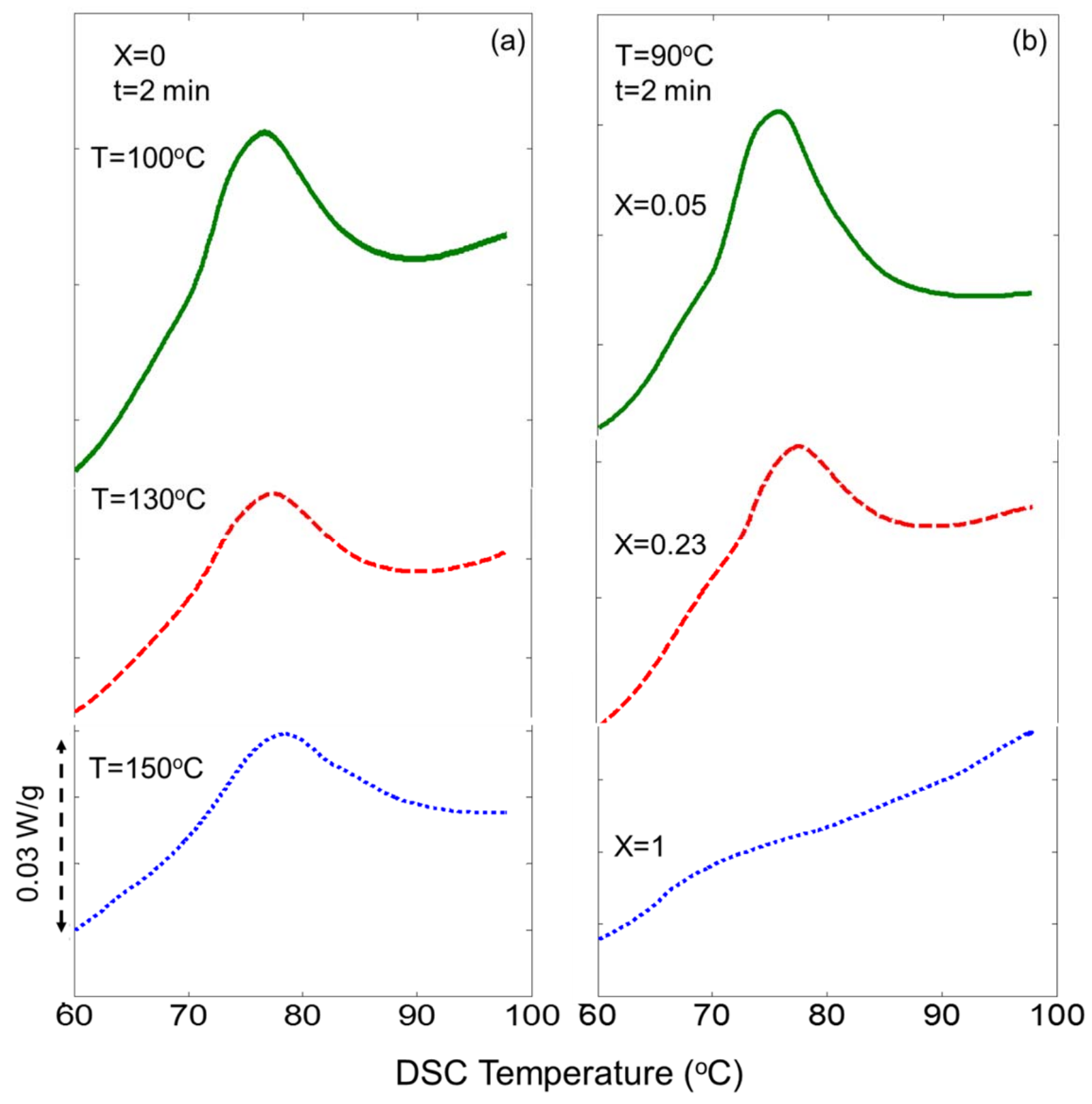

Fig. 1. DSC thermograms showing the dependence of denaturation peaks on (a) previous hold temperature and (b) sample moisture content, after a hold time of 2 minutes. 

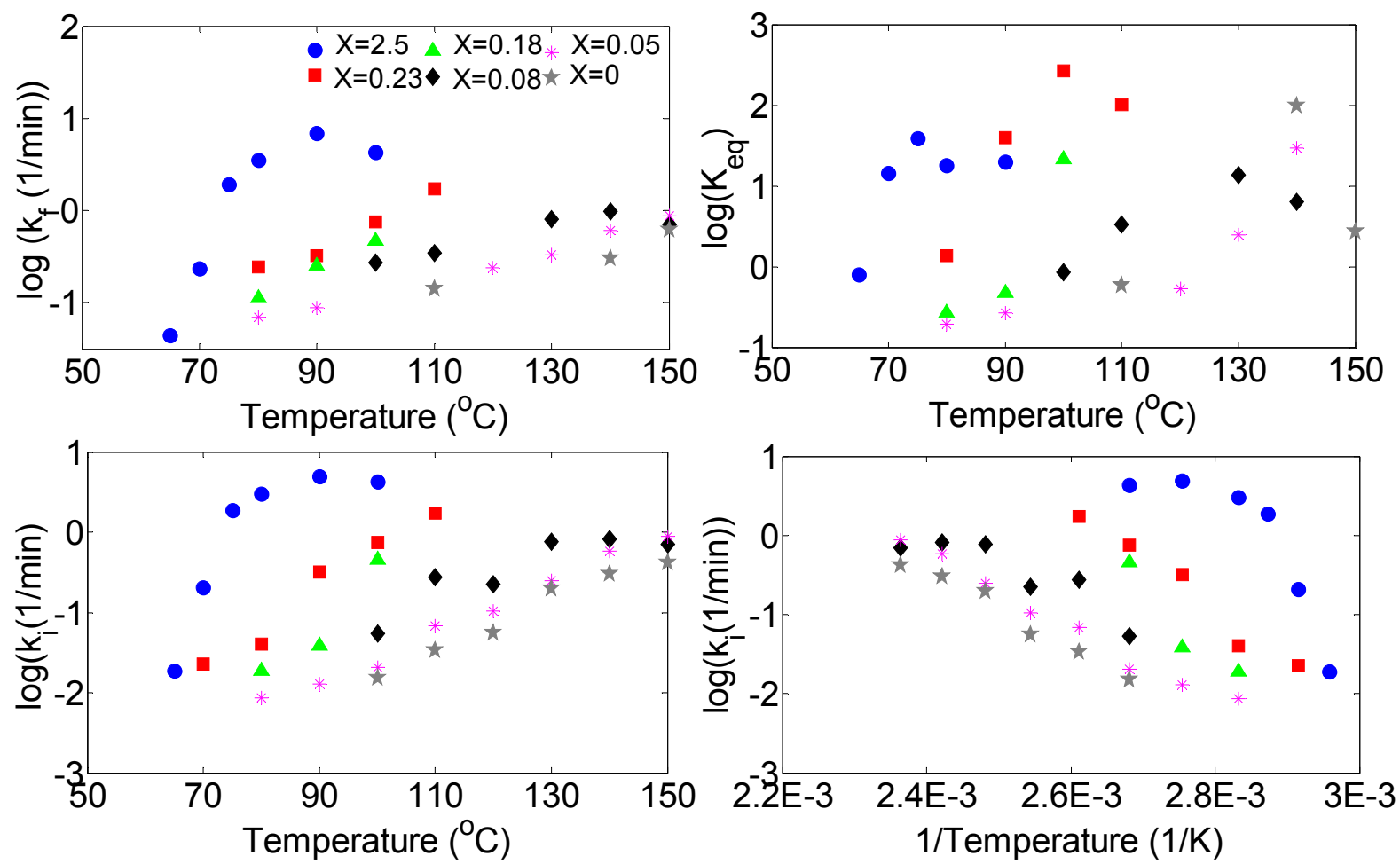

Fig. 2. Logarithms (to the base 10) of the kinetic rate and equilibrium constants plotted versus temperature or inverse temperature, for each moisture content $(X)$. 

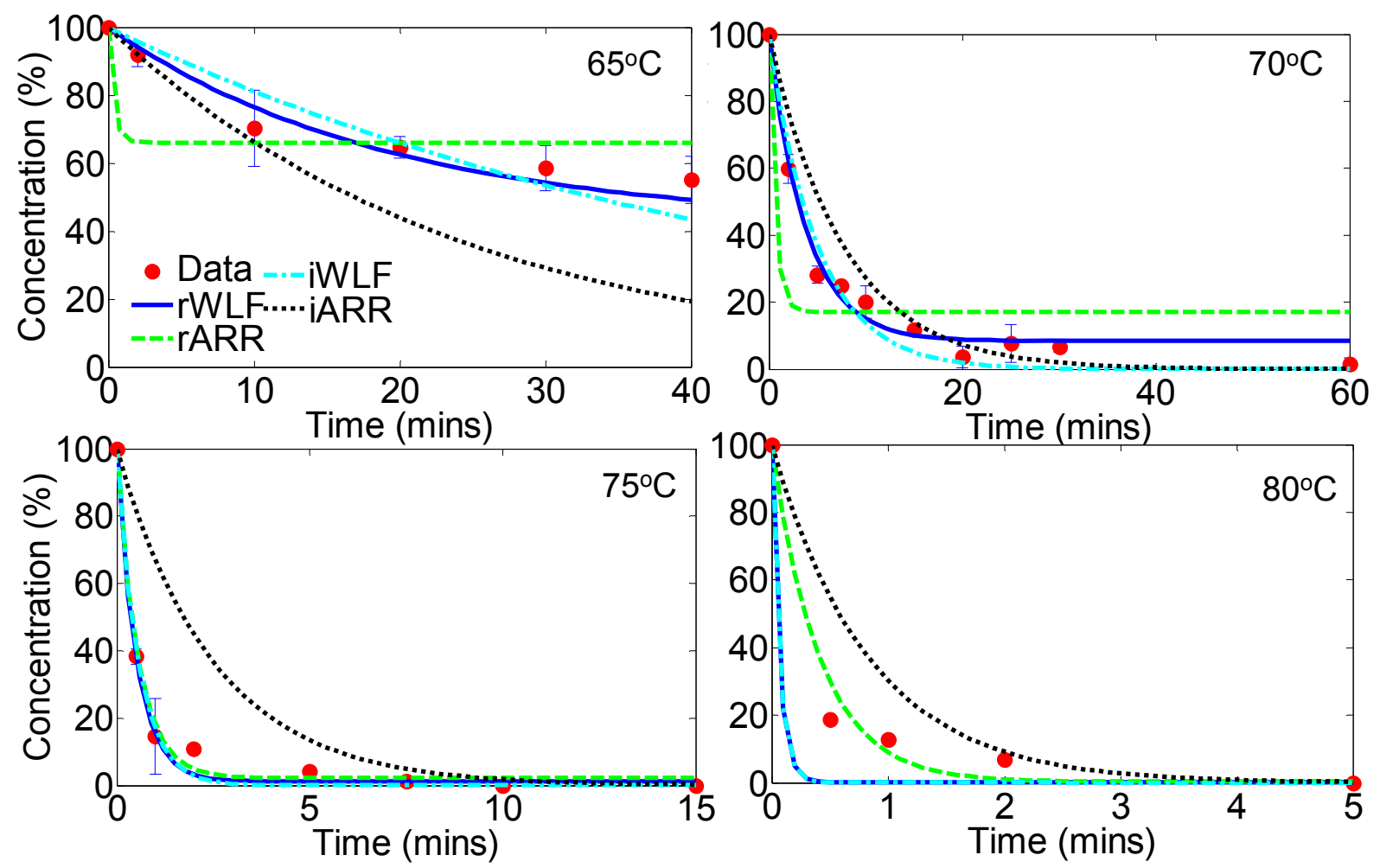

Fig. 3. Evolution of undenatured protein concentration versus time at different temperatures and for a dry basis moisture content $(X)$ of $2.5 \mathrm{~kg} / \mathrm{kg}$. Plots show experimental data and model fits (rWLF - reversible WLF, rARR - reversible Arrhenius, iWLF - irreversible WLF, iARR - irreversible Arrhenius). 

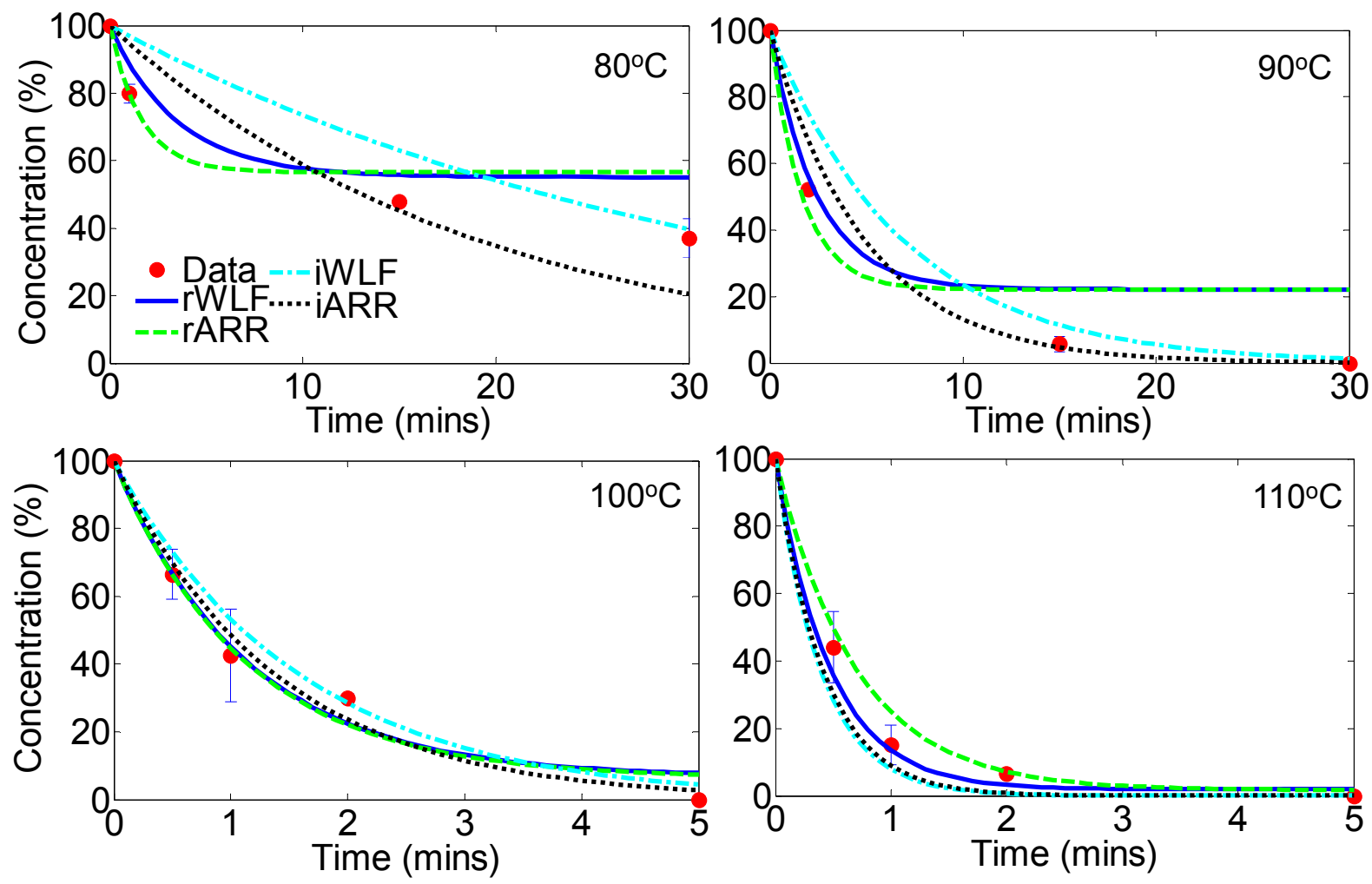

Fig. 4. Evolution of undenatured protein concentration versus time at different temperatures and for a dry basis moisture content $(X)$ of $0.23 \mathrm{~kg} / \mathrm{kg}$. Plots show experimental data and model fits ( $\mathrm{rWLF}$ - reversible WLF, rARR - reversible Arrhenius, iWLF - irreversible WLF, iARR - irreversible Arrhenius). 

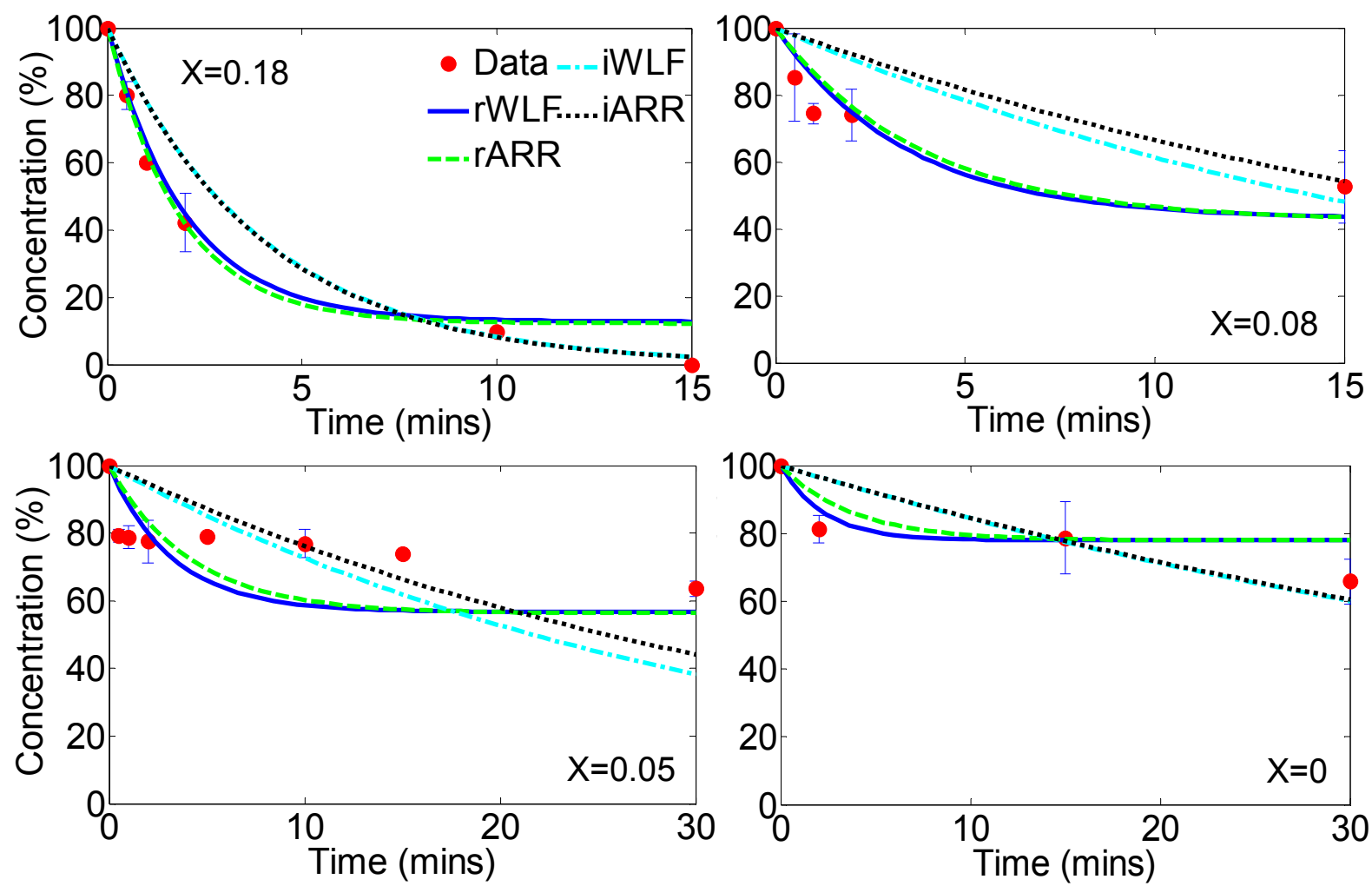

Fig. 5. Evolution of undenatured protein concentration versus time at different dry basis moisture contents $(X)$ and at a temperature of $100^{\circ} \mathrm{C}$. Plots show experimental data and model fits (rWLF - reversible WLF, rARR - reversible Arrhenius, iWLF irreversible WLF, iARR - irreversible Arrhenius). 

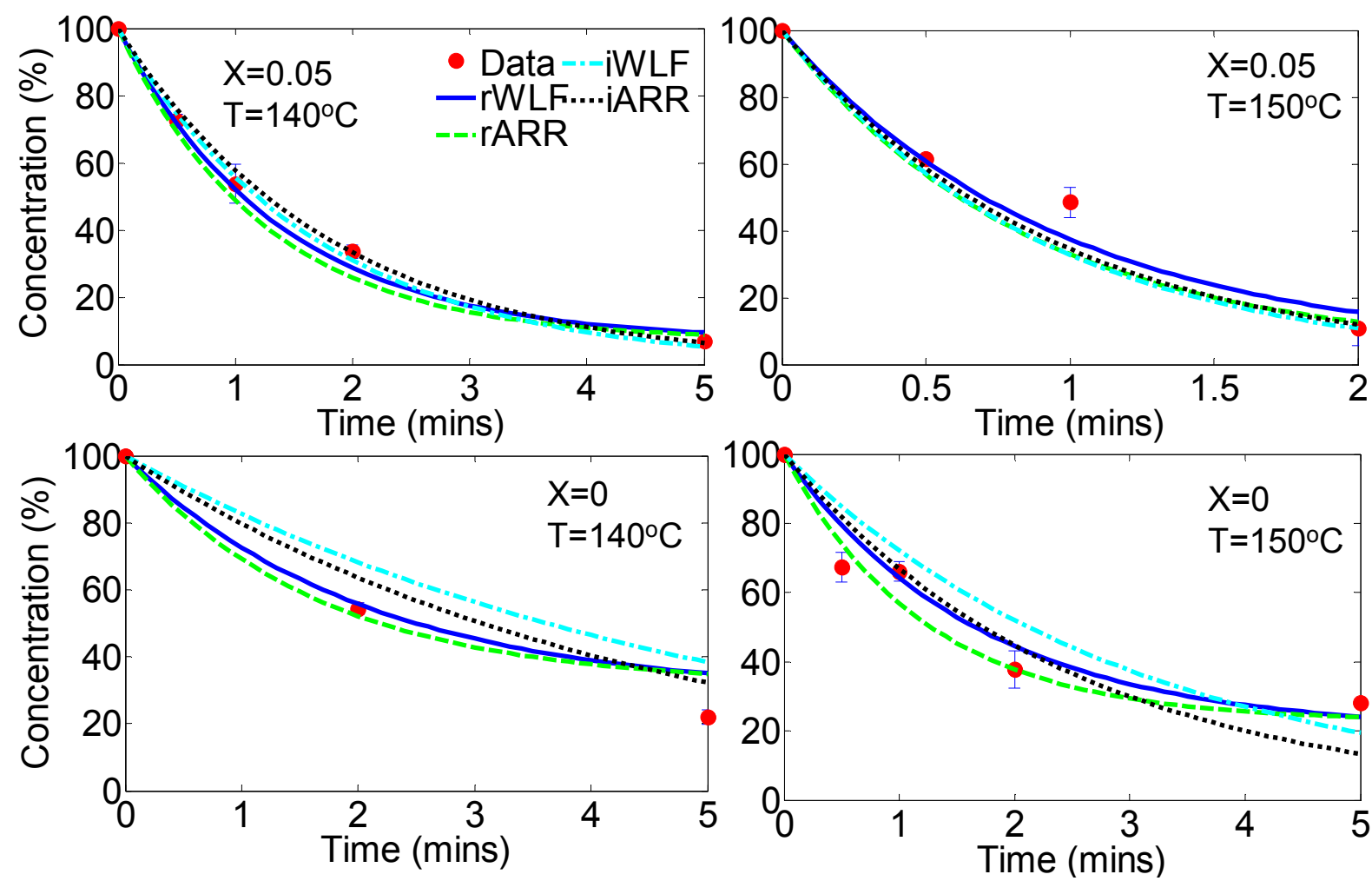

Fig. 6. Evolution of undenatured protein concentration versus time at different dry basis moisture contents $(X)$ and temperatures $(T)$. Plots show experimental data and model fits (rWLF - reversible WLF, rARR - reversible Arrhenius, iWLF - irreversible WLF, iARR - irreversible Arrhenius). 

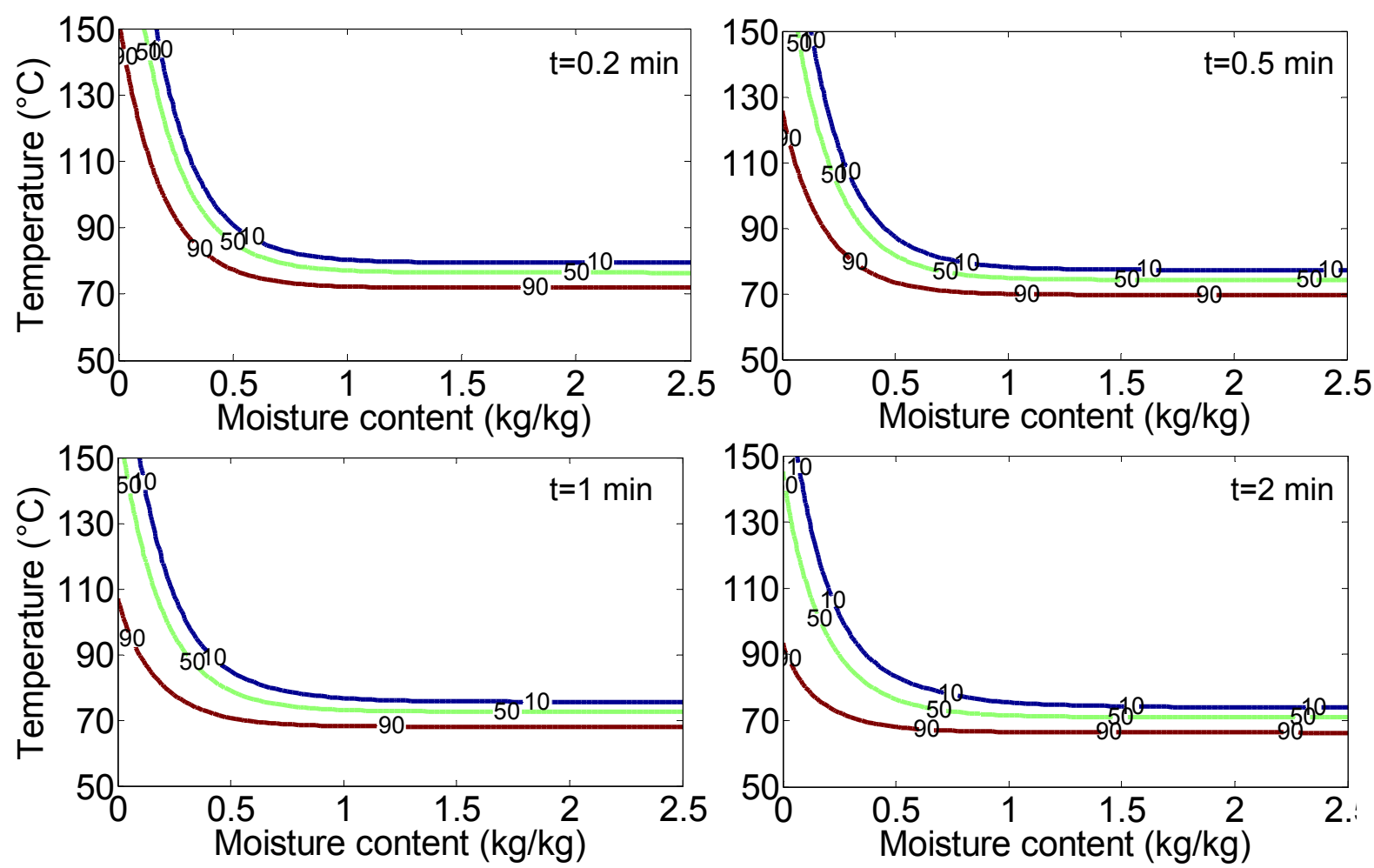

Fig. 7. Lines of equal (percent) undenatured protein concentration at different times (12 $\mathrm{s}, 30 \mathrm{~s}, 1 \mathrm{~min}$ and $2 \mathrm{~min}$ ) 

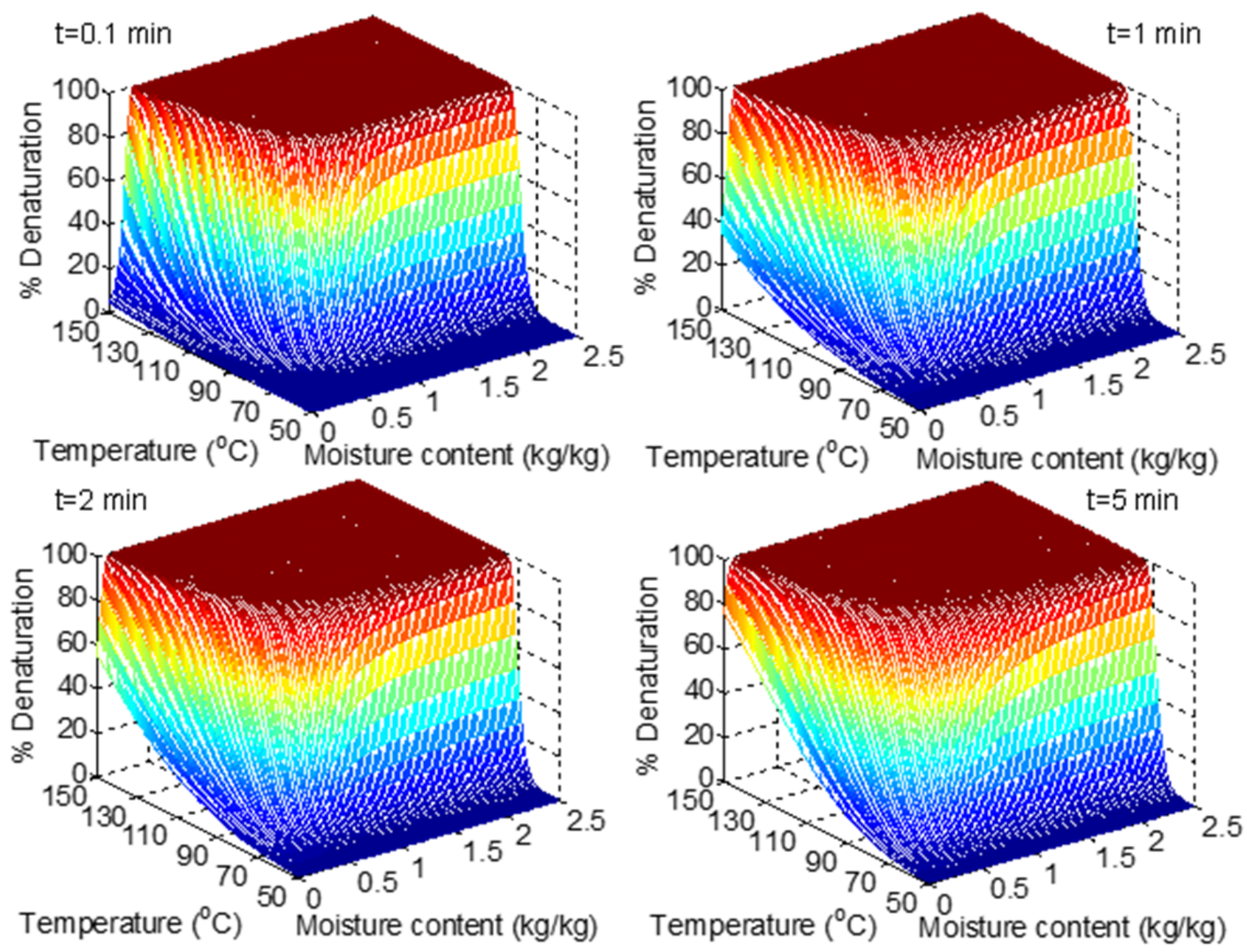

Fig. 8. Surface plots of percentage denaturation against temperature and moisture combinations at different times. 